\title{
Commentary
}

\section{Fluoroscopy During Esophageal Stricture Dilatation: Can It Be Considered Optional?}

\author{
Saroj Kant Sinha, R. Kochhar \\ Department of Gastroenterology, Postgraduate Institute of Medical Education and Research, Chandigarh, India
}

Ingestion of corrosive substances, acid or alkali, is one of the important causes of benign esophageal strictures. Corrosive ingestion is generally accidental in children, but ingestion is usually with suicidal intent in adults. ${ }^{[1,2]}$ In western countries, alkali ingestion is more common than acid ingestion, but acid ingestion is more commonly seen in most parts of India. ${ }^{[1-3]}$ Acidic substances typically cause coagulative necrosis with eschar formation, whereas alkaline substances produce liquefactive necrosis and thus penetrate deep into esophageal wall. ${ }^{[1-3]}$ Severity of corrosive-related injury depends on the concentration of ingested corrosive substance, its amount, position of the patient during and immediately after ingestion, timing of last meal intake, initial treatment received by the patient, etc. ${ }^{[1-4]}$ Risk of formation of esophageal stricture typically depends on the initial grade of injury produced by the intake of corrosive substance, and the risk is higher for a higher grade of injury. ${ }^{[4-6]}$ Esophageal strictures typically develop over several weeks following corrosive esophageal injury; sometimes, it can be delayed even up to a year. ${ }^{[1,2]}$ Development of esophageal stricture typically manifests with dysphagia which needs to be treated to maintain the nutrition and quality of life of these patients.

Corrosive ingestion-related esophageal strictures are most commonly treated initially by endoscopic dilatation which can be performed using bougie dilators such as Savary-Gilliard dilators or a balloon dilator passed through the working channel of endoscope. ${ }^{[7,8]}$ Options for refractory or difficult to dilate esophageal strictures include topical corticosteroid (triamcinolone) injections, topical application or injection of mitomycin C, diathermy incision of strictures, placement of various types of retrievable esophageal stents (plastic, metal, or biodegradable), and surgical treatment. ${ }^{[9-15]}$

Large published experiences are available with both bougie and balloon dilatation of esophageal strictures,

Address for correspondence: Prof. Saroj Kant Sinha, Department of Gastroenterology, PGIMER, Chandigarh - 160 012, India. E-mail: sarojksinha@hotmail.com

This is an open access journal, and articles are distributed under the terms of the Creative Commons Attribution-NonCommercial-ShareAlike 4.0 License, which allows others to remix, tweak, and build upon the work non-commercially, as long as appropriate credit is given and the new creations are licensed under the identical terms. but superiority of one over the other has not been established so far. ${ }^{[1,2]}$ Savary-Gilliard dilator is one of the most widely used bougie dilators as it has been found effective in the dilatation of benign esophageal strictures and offers the operator the advantage of feeling the dilatation occurring under his hands. ${ }^{[1,2]}$ Dilatation of these esophageal strictures is generally started after at least 3-6 weeks of initial injury. The reported risk of esophageal perforation during dilatation of benign esophageal strictures is $0.1 \%-0.4 \% .^{[1,2,14,15]}$ The balloon dilatators are easy to use, convenient, and reasonably safe, but are costly, particularly considering the fact that most of these patients require multiple sessions of esophageal dilatation over several months or years.

Most patients with corrosive ingestion-related esophageal strictures require multiple sessions of endoscopic bougie or balloon dilatation. Dilatation is generally repeated at the interval of 1-4 weeks till successful dilatation of strictures. Criteria for successful dilatation of benign esophageal strictures have varied across different studies and have depended on the method of dilatation. As esophageal perforation is a serious complication, esophageal stricture dilatation needs to be performed by an experienced endoscopist who should be familiar with the intricacies of the procedure and various equipments used. Conventionally, bougie dilatation of benign esophageal strictures is performed over the guidewire under fluoroscopy guidance. The use of fluoroscopy helps in confirmation of passage of guidewire across esophageal stricture and its satisfactory positioning into the stomach. Free passage of guidewire (i.e., passage without any significant resistance) through the stricture is generally confirmed fluoroscopically by checking the guidewire tip position which should be

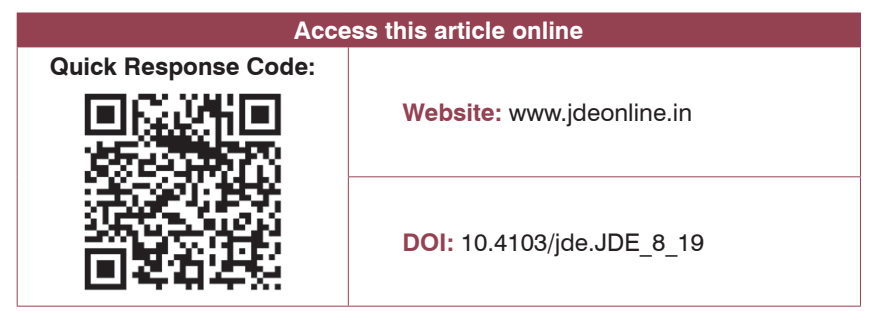

How to cite this article: Sinha SK, Kochhar R. Fluoroscopy during esophageal stricture dilatation: Can it be considered optional?. J Dig Endosc 2018;9:178-80. 
below diaphragm in the region of gastric air shadow. Savary dilator (or most of the other bougie dilators) is passed over the guidewire keeping the guidewire in fixed position with the help of an endoscopy assistant. Position of upper end of the esophageal stricture can be made out fluoroscopically by noting the position of the tip of endoscope. Savary-Gilliard dilators have radiopaque marker at the junction of its dilating segment and shaft. Passage of this radiopaque marker across the esophageal stricture signifies dilation of the esophageal stricture upto the size of that particular dilator. The index dilator is then removed and another bigger size dilator can be passed subsequently in a similar fashion if required. There is risk of guidewire movement and displacement during passage of dilator and exchange of dilator. This can happen inadvertently or due to lack of coordination between the endoscopist and the endoscopy assistant. Thus, the guidewire position is generally checked frequently using fluoroscopy. Additional utility of fluoroscopy lies in early detection of complications such as esophageal perforation. Occurrence of pneumomediastinum and pneumoperitoneum can be detected with fluoroscopy. Further, water-soluble contrast swallow study can be performed at the end of dilatation if there is any suspicion of esophageal perforation. In the event of free or contained esophageal perforation, a nasogastric or nasoduodenal tube placement can also done over a guidewire, for which fluoroscopy guidance is helpful. However, availability of fluoroscopy can be an issue in resource-restricted setting which is not uncommon in developing countries. Experienced endoscopists can feel the free passage of guidewire and can also feel the dilation of esophageal stricture with his or her hand during passage of esophageal bougie dilator. Thus, it is possible to perform esophageal stricture dilatation using bougie dilator without using fluoroscopy. In the current issue of this journal, Bhatt reported her experience of dilatation of corrosive-related esophageal strictures using Savary dilators without using fluoroscopy. ${ }^{[16]}$ Dilatation was successful in $80 \%$ patients, and there was only one esophageal perforation in 180 sessions of dilatations. There is no consensus in published literature on the criteria for successful dilation. In the given study, the authors have used reduction of dysphagia to grade II or less as criteria for successful dilatation which can be debated. However, the study highlights the feasibility of dilation of benign esophageal strictures using Savary dilators even without fluoroscopy. The findings are relevant to the practice of endoscopy in resource-constrained environment. However, it can still not be recommended as standard of care for every hospital and every patient. One alternative approach can be selective use of fluoroscopy, i.e., subjecting relatively easy-to-dilate patients to such procedures without fluoroscopy and selecting the difficult-to-dilate patients to traditional esophageal stricture dilatation procedure under fluoroscopy. Long esophageal strictures, tortuous strictures, multiple strictures, strictures with pseudodiverticulum, and strictures with relatively thick esophageal wall can be relatively difficult to dilate and may require more number of dilatations..$^{[1,2,8,17]}$ However, ease of dilatation may not necessarily mean low risk of complications. Still another approach can be doing first session of esophageal dilatation under fluoroscopy and subsequent sessions of esophageal stricture dilatation without fluoroscopy, particularly when initial session was relatively easy to dilate with favorable stricture characteristics. We still do not have sufficient published literature to support any such strategy, and it is unlikely that any such data will emerge easily because of the involved medicolegal issues with every endoscopic procedure-related complication.

In the current study by Bhatt, $20 \%$ of patients could not be dilated successfully, and these patients had multiple strictures. Patients in the current study were followed up for 1 year which is rather short for a disease like corrosive esophageal stricture. Some of these patients tend to have recurrence of strictures after months and years. Stricture characteristics which define difficult-to-dilate strictures or in whom more number of dilatation sessions are expected include long length of stricture, multiple strictures, tortuous esophageal strictures, strictures with diverticulum, and strictures with relatively thick wall in the involvement segment. ${ }^{[1,2,15,17-19]}$ Treatment options in these patients include local steroid injection (triamcinolone) during dilatation sessions, topical mitomycin $\mathrm{C}$ application with dilatation, diathermy incision with or without dilatation, and placement of various types of removable esophageal stents (plastic, metal, or biodegradable). ${ }^{[9-15,19]}$ Local steroid injection into the stricture and topical mitomycin $\mathrm{C}$ application have been found useful in this subset of difficult to treat patients, who otherwise would be considered for major surgical procedure. Removable esophageal stents are also useful in them. It is unclear which is the preferred option in patients with refractory esophageal stricture or difficult-to-dilate esophageal stricture as there is paucity of comparative data and randomized control trials comparing them or using a combination of them.

Surgical treatment in patients with benign esophageal stricture is generally restricted to failed endoscopic 
treatment (one modality, more than one modality, or a combination of modalities - depends on local practice and experience) and major complications related to endoscopic treatment like free esophageal perforation..$^{[1,2,20-23]}$ Contained esophageal perforations are not uncommon after esophageal stricture dilatations, and most of the patients improve with conservative treatment, as happened in the current study also. However, patients with free esophageal perforation or who develop organ failure usually require surgery, but some endoscopic options such as glue injection, endoscopic clip application, and covered esophageal metal stent placement have started emerging. Surgical procedures in these patients usually include esophageal replacement with colonic or gastric transposition. Cervical strictures can be repaired with myocutaneous flaps. ${ }^{[20-23]}$

Despite the data shown in the current study which has a small sample size, the use of fluoroscopy during dilatation of esophageal stricture is likely to remain the standard of care for these patients. However, in specific situations and resource-limited environment, these data will be useful to justify the dilatation of esophageal stricture without fluoroscopy.

\section{REFERENCES}

1. Chirica M, Bonavina L, Kelly MD, Sarfati E, Cattan P. Caustic ingestion. Lancet 2017;389:2041-52.

2. Contini S, Scarpignato C. Caustic injury of the upper gastrointestinal tract: A comprehensive review. World J Gastroenterol 2013;19:3918-30.

3. Zargar SA, Kochhar R, Nagi B, Mehta S, Mehta SK. Ingestion of strong corrosive alkalis: Spectrum of injury to upper gastrointestinal tract and natural history. Am J Gastroenterol 1992;87:337-41.

4. Zargar SA, Kochhar R, Mehta S, Mehta SK. The role of fiberoptic endoscopy in the management of corrosive ingestion and modified endoscopic classification of burns. Gastrointest Endosc 1991;37:165-9.

5. Kay M, Wyllie R. Caustic ingestions in children. Curr Opin Pediatr 2009;21:651-4.

6. Zargar SA, Kochhar R, Nagi B, Mehta S, Mehta SK. Ingestion of corrosive acids. Spectrum of injury to upper gastrointestinal tract and natural history. Gastroenterology 1989;97:702-7.

7. Kim JH, Song HY, Kim HC, Shin JH, Kim KR, Park SW, et al. Corrosive esophageal strictures: Long-term effectiveness of balloon dilation in 117 patients. J Vasc Interv Radiol 2008;19:736-41.

8. Cakmak M, Boybeyi O, Gollu G, Kucuk G, Bingol-Kologlu M,
Yagmurlu A, et al. Endoscopic balloon dilatation of benign esophageal strictures in childhood: A 15-year experience. Dis Esophagus 2016;29:179-84.

9. Kochhar R, Ray JD, Sriram PV, Kumar S, Singh K. Intralesional steroids augment the effects of endoscopic dilation in corrosive esophageal strictures. Gastrointest Endosc 1999;49:509-13.

10. Berger M, Ure B, Lacher M. Mitomycin C in the therapy of recurrent esophageal strictures: Hype or hope? Eur J Pediatr Surg 2012;22:109-16.

11. Dall'Oglio L, Caldaro T, Foschia F, Faraci S, Federici di Abriola G, Rea F, et al. Endoscopic management of esophageal stenosis in children: New and traditional treatments. World $\mathrm{J}$ Gastrointest Endosc 2016;8:212-9.

12. Karakan T, Utku OG, Dorukoz O, Sen I, Colak B, Erdal H, et al. Biodegradable stents for caustic esophageal strictures: A new therapeutic approach. Dis Esophagus 2013;26:319-22.

13. Repici A, Vleggaar FP, Hassan C, van Boeckel PG, Romeo F, Pagano $\mathrm{N}$, et al. Efficacy and safety of biodegradable stents for refractory benign esophageal strictures: The BEST (Biodegradable esophageal stent) study. Gastrointest Endosc 2010;72:927-34.

14. Nijhawan S, Udawat HP, Nagar P. Aggressive bougie dilatation and intralesional steroids is effective in refractory benign esophageal strictures secondary to corrosive ingestion. Dis Esophagus 2016;29:1027-31.

15. Pace F, Antinori S, Repici A. What is new in esophageal injury (infection, drug-induced, caustic, stricture, perforation)? Curr Opin Gastroenterol 2009;25:372-9.

16. Bhatt VR, Kakrani AL. A clinical study of the use of savary-gilliard dilators in corrosive esophageal strictures without the use of fluoroscopy: a reality in resource-limited settings in a developing country. J Digestion Endosc 2018;4:159-64.

17. Lahoti D, Broor SL, Basu PP, Gupta A, Sharma R, Pant CS, et al. Corrosive esophageal strictures: Predictors of response to endoscopic dilation. Gastrointest Endosc 1995;41:196-200.

18. Tharavej C, Pungpapong SU, Chanswangphuvana P. Outcome of dilatation and predictors of failed dilatation in patients with acid-induced corrosive esophageal strictures. Surg Endosc 2018;32:900-7.

19. Siersema PD, de Wijkerslooth LR. Dilation of refractory benign esophageal strictures. Gastrointest Endosc 2009;70:1000-12.

20. Varshney VK, Saluja SS, Mishra PK, Sisodia K, Sachan A, Sheetal $\mathrm{P}$, et al. Utilization of gastric conduit in the management of combined corrosive esophageal and stomach stricture. World J Surg 2018;42:211-7.

21. Gupta NM, Gupta R. Transhiatal esophageal resection for corrosive injury. Ann Surg 2004;239:359-63.

22. Zhou JH, Jiang YG, Wang RW, Lin YD, Gong TQ, Zhao YP, et al. Management of corrosive esophageal burns in 149 cases. J Thorac Cardiovasc Surg 2005;130:449-55.

23. Ezemba N, Eze JC, Nwafor IA, Etukokwu KC, Orakwe OI. Colon interposition graft for corrosive esophageal stricture: Midterm functional outcome. World J Surg 2014;38:2352-7. 